\title{
Определение селективных модуляторов андрогенных рецепторов в биологически активных добавках методом жидкостной хромато-масс-спектрометрии
}

\author{
Дмитриева Е.В., Азарян А.А. \\ Кубанский государственный университет, Краснодар
}

Поступила в редакцию 23.08.2019 г.

DOI: 10.17308/sorpchrom.2019.19/1169

Изучена возможность одновременного определения нескольких селективных модуляторов андрогенных рецепторов (САРМов) наряду с соединениями, распространяемыми под видом САРМов, в биологически активных добавках, приобретенных через интернет. Оптимизированы условия хроматографического разделения аналитов с использованием различных колонок и систем элюентов, а также масс-спектрометрического детектирования с применением тройного квадрупольного и квадруполь-времяпролетного масс-анализаторов. Методика использована для анализа биологически активных добавок, приобретенных через интернет, в составе которых заявлены целевые аналиты.

Ключевые слова: САРМ, ВЭЖХ, масс-спектрометрия, спортивное питание

\section{Determination of selective androgen receptor modulators in biologically active supplements by liquid chromato- graphy-mass spectrometry}

\author{
Dmitrieva E.V., Azaryan A.A. \\ Kuban State University, Krasnodar
}

Nowadays a considerable amount of biologically active supplements containing prohibited or not passed through the clinical trials compounds is being distributed via internet, therefore, there is a need for the development of procedures to control them. Among such compounds, selective androgen receptor modulators (SARMs) possessing high anabolic effects and reduced side effects comparing to traditional anabolic steroids are one of the most popular compounds. Even though these compounds have not passed through the clinical trials, SARM effects on human body resulted in their popularization, that is why they were added to the Prohibited List of the World Anti-Doping Agency (WADA) in 2008. Moreover, nowadays compounds related to other classes and are being distributed under the guise of SARMs and most of them are prohibited by WADA as well, that is why they should also be controlled.

A procedure for the quantification of selective androgen receptor modulators as well as compounds distributed under the guise of SARMs via internet has been developed. During the optimization of chromatographic separation conditions, the use of Luna Omega Polar C18 $(2.1 \times 100 \mathrm{~mm}, 1.6 \mu \mathrm{m})$ column and $0.1 \%$ formic acid in water: $0.1 \%$ formic acid in methanol system using gradient elution was found to be optimum. Detection of analytes was conducted with the use of a triple quadrupole mass-spectrometer with heated electrospray ionization operating in negative and positive ion detection modes. To confirm the presence of declared analytes, high resolution mass-spectrometry, namely a quadrupole-time of flight mass analyzer with electrospray ionization, was applied. The procedure was used to analyze biologically active supplements comprising targeted analytes to determine the contents of these analytes. As a result, the contents of analytes in Ligandrol, Miostop+, Ostarine+, Sarmastol, Radarine drugs correlated with the declared values, while for 
Andarine, Endorol, Ibutamoren, Reverol+ a deviation from the declared contents was observed (contents were in the range of $41-83 \%$ from the declared values).

Keywords: SARM, HPLC, mass-spectrometry, sports nutrition

\section{Введение}

В настоящее время известен широкий спектр биологически активных добавок и вспомогательных препаратов для спортсменов, приобретение которых возможно через интернет [1]. Помимо традиционных анаболических стероидов, известных достаточно длительное время, в последние годы широкое распространение на черном рынке получили их синтетические аналоги - селективные модуляторы андрогенных рецепторов, также обладающие анаболическим действием, наряду с меньшими, либо отличающимися от стероидных гормонов, побочными эффектами [2-4]. Несмотря на то, что данные соединения не прошли клинические испытания, заявляемая эффективность способствовала не только их популяризации, но и привела к распространению под видом САРМов препаратов, относящихся к другим классам. Например, SR-9009 является Rev-Erb $\alpha$ агонистом [5], а MK-677 - секретагог гормона роста непептидной природы [6], которые обладают схожим эффектом на организм человека. В последствии, их фармакологическое действие на организм человека привело к внесению их в Запрещенный список Всемирного антидопингового агентства [7].

Ранее были опубликованы исследования, посвященные определению некоторых селективных модуляторов андрогенных рецепторов в фармацевтических субстанциях, приобретенных на черном рынке, например, S-4 (андарин) [8], LDG-4033 (лигандрол) $[1,9,10]$, S-22 (остарин) [10], присутствующих в исследуемых образцах в качестве примесей или основных соединений. Стоит отметить, именно этими соединениями, согласно отчету ВАДА, спортсмены злоупотребляют особенно часто [11]. Тем не менее, исследования, посвященные определению селективных модуляторов андрогенных рецепторов в продуктах, приобретенных на черном рынке носят единичный и разрозненный характер.

Таким образом, вследствие широкого распространения данных препаратов, в настоящее время существует необходимость в разработке методик их определения не только в качестве превентивной меры в допинг-контроле, но и для контроля качества препаратов, реализуемых через интернет и содержащих запрещенные соединения. Следовательно, цель данного исследования заключалась в разработке способа определения селективных модуляторов андрогенных рецепторов, а также соединений, распространяемых под их видом, в биологически активных добавках, реализуемых через интернет.

\section{Эксперимент}

Приборы и оборудование. В ходе проведения исследования использовали систему, состоящую из ультравысокоэффективного жидкостного хроматографа Dionex Ultimate 3000 и тройного квадрупольного масс-спектрометра Thermo TSQ Access Max (Сан-Хосе, США). Для подтверждения подлинности соединений в фармацевтических препаратах использовали ультравысокоэффективный жидкостный хроматограф Bruker Elute в сочетании с квадруполь-времяпролетным массспектрометром высокого разрешения Bruker Maxis Impact (Бремен, Германия). Оптимизация условий разделения аналитов проводилась с использованием следующих хроматографических колонок: Kinetex Phenyl-Hexyl (2.1×100 мм, 1.7 мкм), Luna 
Omega Polar C18 (2.1×100 мм, 1.6 мкм), Kinetex C18 (2.1×100 мм, 1.7 мкм), ACQUITY UPLC BEH C18 (2.1×100 мм, 1.7 мкм), Accucore C18 (2.1×100 мм, 2.6 мкм).

Условия масс-спектрометрического детектирования. Детектирование с использованием тройного квадрупольного масс-спектрометра проводилось в следующих условиях: напряжение на источнике ионизации - +4/-3 кВ, температура испарителя $-400^{\circ} \mathrm{C}$, температура трансферного капилляра $-320^{\circ} \mathrm{C}$, расход газа-распылителя - 60 усл. ед., расход вспомогательного газа - 15 усл. ед., давление газа-мишени (аргон) в ячейка соударений - 1.5 мторр.

Реактивы и материалы. Стандартные образцы определяемых веществ были приобретены у Shanghai Soyoung Biotech. Inc. (Китай). В качестве растворителей и компонентов подвижной фазы использовали ацетонитрил (Biosolve, Израиль) и метанол (J.T.Baker, Нидерланды) квалификации «для ВЭЖХ», муравьиную кислоту (Acros Organics, 98\%). Воду (18.2 M $\Omega$ ) получили с помощью системы Milli-Q.

Приготовление стандартных растворов. Исходные растворы определяемых аналитов с концентрацией $1 \mathrm{mг} / \mathrm{cm}^{3}$ готовили путем растворения точной навести вещества в ацетонитриле. Рабочие растворы готовили путем последовательного разбавления водой растворов, полученных из головного. Для проведения количественного анализа, готовили стандартные растворы определяемых соединений с концентрациями, соответствующими $80,90,100,110,120 \%$ от номинального содержания аналита путем разбавления исходных растворов водой. Все растворы хранили при температуре $4^{\circ} \mathrm{C}$ не более месяца.

Приготовление растворов биологически активных добавок. Содержимое 10 капсул биологически активных добавок (табл. 1) гомогенизировали, после чего отбирали навеску, соответствующую массе одной капсулы, которую растворяли в $30 \mathrm{~cm}^{3}$ ацетонитрила и подвергали ультразвуковому воздействую в течение 5 мин, после чего доводили раствор до метки в мерной колбе на $50 \mathrm{~cm}^{3}$. Аликвоту полученного раствора последовательно разбавляли водой до конечной концентрации 10 мкг/см ${ }^{3}$ для последующего хромато-масс-спектрометрического анализа. Проводили 5 параллельных определений аналитов.

Таблица 1. Исследуемые вещества

\begin{tabular}{|c|c|c|c|c|}
\hline $\begin{array}{c}\text { Название } \\
\text { биологически } \\
\text { активной до- } \\
\text { бавки }\end{array}$ & Аналит & $\begin{array}{c}\text { Содержание } \\
\text { аналита, мг }\end{array}$ & Структурная формула аналита & Производитель \\
\hline 1 & 2 & 3 & & 5 \\
\cline { 1 - 6 } Andarine & $\mathrm{S}-4$ & 25 & 5 &
\end{tabular}




\begin{tabular}{|c|c|c|c|c|}
\hline 1 & 2 & 3 & 4 & 5 \\
\hline Ibutamoren & $\begin{array}{l}\text { MK- } \\
677\end{array}$ & 25 & & $\begin{array}{l}\text { Ligandbiotech, } \\
\text { Китай }\end{array}$ \\
\hline Ostarine+ & $\begin{array}{l}\text { MK- } \\
2866\end{array}$ & 25 & & $\begin{array}{c}\text { Envenom } \\
\text { Pharm, США }\end{array}$ \\
\hline Miostop+ & YK-11 & 10 & & $\begin{array}{c}\text { Envenom } \\
\text { Pharm, США }\end{array}$ \\
\hline Sarmastol & $\begin{array}{c}\text { AC- } \\
262536\end{array}$ & 10 & & $\begin{array}{c}\text { Envenom } \\
\text { Pharm, США }\end{array}$ \\
\hline Radarine & $\begin{array}{l}\text { RAD- } \\
140\end{array}$ & 10 & & $\begin{array}{c}\text { Envenom } \\
\text { Pharm, США }\end{array}$ \\
\hline
\end{tabular}

Оптимизация условий разделения и детектирования аналитов. Изучение параметров удерживания в режиме обращено-фазовой хроматографии проводилось с использованием различных аналитических колонок с октадецильным и фенилгексильным сорбентами. В качестве подвижной фазы использовали системы метанол:вода и ацетонитрил:вода, с добавлением $0.1 \%$ муравьиной кислоты. Детектирование в режиме регистрации положительно и отрицательно заряженных ионов проводили с использованием источников электрораспылительной (для QTOF) и нагреваемой электрораспылительной (для QqQ) ионизации.

\section{Обсуждение результатов}

Оптимизация условий разделения и детектирования аналитов. В ходе проведения оптимизации хроматографического разделения установили, что оптимальным является использование системы метанол:вода с добавлением $0.1 \%$ муравьиной кислоты, поскольку при использовании системы ацетонитрил:вода, содержащей $0.1 \%$ муравьиную кислоту, на хроматограммах отсутствовал пик LGD-4033 как на колонке с октадецильным, так и фенил-гексильным сорбентом. В качестве неподвижной фазы выбрали сорбент с октадецильной фазой, поскольку фенил-гексильный сорбент приводил к неудовлетворительному разрешению пиков анализируемых соединений при использовании различных программ градиентного элюирования.

Сопоставление колонок с октадецильной фазой показало, что наилучшие результаты достигаются на колонке Luna Omega Polar C18 (2.1×100 мм, 1.6 мкм) с использованием системы элюентов $0.1 \%$ муравьиная кислота в воде:0.1\% муравьиная кислота в метаноле (элюенты А и Б, соответственно) в режиме градиентного элюирования при скорости потока подвижной фазы $0.4 \mathrm{~cm}^{3} /$ мин. Программа градиентного 
элюирования следующая: 0.0 мин - 90\% А, 1.0 мин - 90\% А, 3.0 мин - 35\% А, 5.0 мин - 10\% А, 6.0 мин - 10\% А, 6.0 мин - 90\% А, 7.5 мин - 90\% А. Хроматограмма соединений, полученная в оптимальных условиях, показана на рис. 1. Программа детектирования аналитов в режиме мониторинга выбранных реакций представлена в табл. 2.

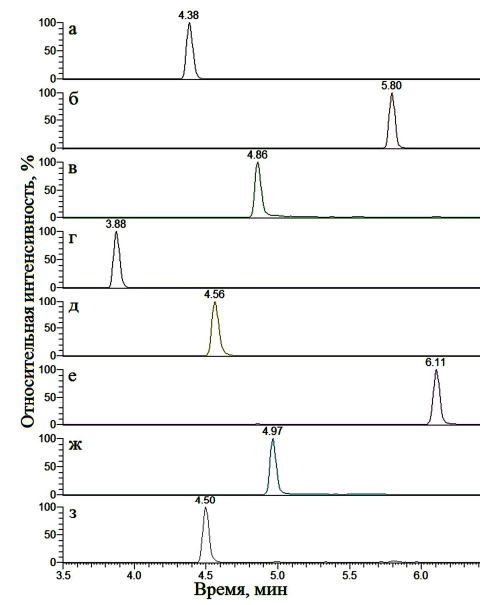

Рис. 1. Хроматограмма, полученная в оптимальных условиях: a - S-4, б - SR-9009, в - LGD-4033, г - MK-677, д - S-22, е - YK-11, ж - AC-262536, 3 - RAD-140.

Таблица 2. Программа определения аналитов в режиме мониторинга нескольких реакций

\begin{tabular}{|c|c|c|c|c|c|}
\hline Аналит & $\begin{array}{c}\text { Ион- } \\
\text { предшественник, } \\
\mathrm{m} / \mathrm{z} \\
\end{array}$ & $\begin{array}{c}\text { Ион- } \\
\text { продукт, } \\
\mathrm{m} / \mathrm{z}\end{array}$ & $\begin{array}{l}\text { Энергия со- } \\
\text { ударений, эВ }\end{array}$ & $\begin{array}{c}\text { Напряжение на } \\
\text { экстрагирующей } \\
\text { линзе, В }\end{array}$ & $\begin{array}{l}\text { Время удер- } \\
\text { живания, мин }\end{array}$ \\
\hline 1 & & & & & \\
\hline \multirow{3}{*}{ S-4 } & \multirow{3}{*}{440.0} & 150.0 & 23 & \multirow{3}{*}{-63} & \multirow{3}{*}{4.38} \\
\hline & & 260.9 & 24 & & \\
\hline & & 204.9 & 31 & & \\
\hline $\begin{array}{c}\text { SR- } \\
9009\end{array}$ & 438.1 & 125.0 & 30 & 56 & 5.80 \\
\hline \multirow{3}{*}{$\begin{array}{l}\text { LGD- } \\
4033\end{array}$} & \multirow{3}{*}{339.1} & 240.0 & 24 & \multirow{3}{*}{88} & \multirow{3}{*}{4.85} \\
\hline & & 220.0 & 27 & & \\
\hline & & 199.0 & 28 & & \\
\hline \multirow{3}{*}{$\begin{array}{l}\text { MK- } \\
677\end{array}$} & \multirow{3}{*}{529.2} & 263.0 & 15 & \multirow{3}{*}{77} & \multirow{3}{*}{3.88} \\
\hline & & 267.1 & 19 & & \\
\hline & & 235.0 & 22 & & \\
\hline \multirow{3}{*}{ S-22 } & \multirow{3}{*}{388.0} & 268.9 & 21 & \multirow{3}{*}{-46} & \multirow{3}{*}{4.57} \\
\hline & & 118.0 & 40 & & \\
\hline & & 185.0 & 40 & & \\
\hline \multirow{3}{*}{ YK-11 } & \multirow{3}{*}{399.2} & 357.1 & 10 & \multirow{3}{*}{57} & \multirow{3}{*}{6.12} \\
\hline & & 325.1 & 16 & & \\
\hline & & 307.1 & 23 & & \\
\hline \multirow{3}{*}{$\begin{array}{c}\text { AC- } \\
262536\end{array}$} & \multirow{3}{*}{279.1} & 169.1 & 23 & \multirow{3}{*}{55} & \multirow{3}{*}{4.97} \\
\hline & & 195.1 & 24 & & \\
\hline & & 193.1 & 36 & & \\
\hline \multirow{2}{*}{$\begin{array}{c}\text { RAD- } \\
140 \\
\end{array}$} & \multirow{2}{*}{394.0} & 223.0 & 13 & \multirow{2}{*}{82} & \multirow{2}{*}{4.50} \\
\hline & & 170.0 & 30 & & \\
\hline
\end{tabular}

Подтверждение подлинности соединений в биологически активных добавках проводилось с применением масс-спектрометрии высокого разрешения путем на- 
пуска приготовленных растворов в камеру источника электрораспылительной ионизации. Полученные результаты представлены в табл. 3. Стоит отметить, что YK-11 подвержен значительной фрагментации в источнике ионизации с отрывом метанола от протонированного молекулярного иона [12], поэтому пик молекулярного иона детектировать в данных условиях не представлялось возможным.

Таблица 3. Результаты анализа фармацевтических препаратов методом массспектрометрии высокого разрешения

\begin{tabular}{|c|c|c|c|c|c|}
\hline Аналит & $\begin{array}{c}\text { Элементный } \\
\text { состав }\end{array}$ & $\begin{array}{c}\text { Теоретическая } \\
\text { моноизотопная } \\
\text { масса, Да }\end{array}$ & $\begin{array}{c}\text { Молекулярная масса } \\
\text { протонированного/ } \\
\text { депротонированного } \\
\text { иона, Да }\end{array}$ & $\begin{array}{c}\text { Найденная } \\
\text { масса, Да }\end{array}$ & $\begin{array}{c}\text { Точность } \\
\text { определения } \\
\text { масс* }\end{array}$ \\
\hline $\mathrm{S}-4$ & $\mathrm{C}_{19} \mathrm{H}_{18} \mathrm{~F}_{3} \mathrm{~N}_{3} \mathrm{O}_{6}$ & 441.1148 & 440.1075 & 440.1079 & 0.9 \\
\hline $\begin{array}{c}\mathrm{SR}- \\
9009\end{array}$ & $\mathrm{C}_{20} \mathrm{H}_{24} \mathrm{ClN}_{3} \mathrm{O}_{4} \mathrm{~S}$ & 437.1176 & 438.1249 & 438.1251 & 0.5 \\
\hline $\begin{array}{c}\mathrm{LGD}- \\
4033\end{array}$ & $\mathrm{C}_{14} \mathrm{H}_{12} \mathrm{~F}_{6} \mathrm{~N}_{2} \mathrm{O}$ & 338.0854 & 339.0927 & 339.0928 & 0.3 \\
\hline $\begin{array}{c}\mathrm{MK}- \\
677\end{array}$ & $\mathrm{C}_{27} \mathrm{H}_{36} \mathrm{~N}_{4} \mathrm{O}_{5} \mathrm{~S}$ & 528.2406 & 529.2479 & 529.2391 & -1.3 \\
\hline $\mathrm{S}-22$ & $\mathrm{C}_{19} \mathrm{H}_{14} \mathrm{~F}_{3} \mathrm{~N}_{3} \mathrm{O}_{3}$ & 389.0987 & 388.0914 & 388.0917 & 0.8 \\
\hline $\mathrm{YK}-11$ & $\mathrm{C}_{25} \mathrm{H}_{34} \mathrm{O}_{6}$ & 430.2355 & 431.2428 & 399.2163 & - \\
\hline $\begin{array}{c}\mathrm{AC}- \\
262536\end{array}$ & $\mathrm{C}_{18} \mathrm{H}_{18} \mathrm{~N}_{2} \mathrm{O}$ & 278.1419 & 279.1492 & 279.1493 & 0.4 \\
\hline $\begin{array}{c}\mathrm{RAD} \\
140\end{array}$ & $\mathrm{C}_{20} \mathrm{H}_{16} \mathrm{ClN}_{5} \mathrm{O}_{2}$ & 393.0993 & 394.1065 & 394.1067 & 0.5 \\
\hline
\end{tabular}

*выраженная в миллионных долях (ppm)

Анализ биологически активных добавок. Как уже было отмечено ранее, градуировочные зависимости строились по 5 точкам: 80, 90, 100, 110, $120 \%$ от указанного на упаковке содержания аналита. В результате проведенного анализа установили, что содержания заявленных соединений в препаратах Ligandrol, Miostop+, Ostarine+, Sarmastol, Radarine находятся в границах указанных на упаковке содержаний, в то время как для Andarine, Endorol, Ibutamoren, Reverol+ наблюдалось отклонение от заявленного содержания (содержание в диапазоне 41-83\% от номинального).

\section{Заключение}

Незаконное распространение биологически активных добавок, содержащих запрещенные вещества, требует разработки методик их определения в данных препаратах. Учитывая, что в данных добавках содержания аналитов могут откланяться от заявленных, становится важным контролировать их качество.

Данная работа выполнена в рамках проекта № 4.2612.2017/ПЧ Минобрнауки РФ и при финансовой поддержке РФФИ, проект № 19-43-233001 p_мол_а, с использованием научного оборудования ЦКП «Эколого-аналитический иентр» Кубанского государственного университета уникальный идентификатор иееттра RFMEFI59317X0008.

\section{Список литературы}

1. Geldof L., Pozo O.J., Lootens L., Morthier W. et al. // Drug Test. Anal. 2017. Vol. 9. pp. 168-178.
2. Geyer H., Schänzer W., Thevis M. // Br. J. Sports Med. 2014. Vol. 48. pp. 820-826. 
3. Gao W., Dalton J.T. // Drug Discov. Today. 2007. Vol. 12. pp. 241-248.

4. Choi S.M., Lee B.M. // Expert Opin. Drug Saf. 2015. Vol. 14. pp. 1773-1785.

5. Geldof L., Deventer K., Roels K., Tudela E. et al. // Int. J. Mol. Sci. 2016. Vol. 17. pii: E1676.

6. Constanzer M.L., Chavez-Eng C.M., Matuszewski B.K. // J. Chromatogr. B. Biomed. Sci. Appl. 1997. Vol. 693. pp. 131-137.

7. World Anti-Doping Agency. The World Anti-Doping Code. The 2019 Prohibited List. International Standard. Режим доступа: https://www.wada-

ama.org/sites/default/files/wada_2019_english_ prohibited_list.pdf (дата обращения: 19.08.2019).

\section{References}

1. Geldof L., Pozo O.J., Lootens L., Morthier W. et al., Drug Test. Anal., 2017, Vol. 9, pp. 168-178. DOI: $10.1002 / \mathrm{dta}$

2. Geyer H., Schänzer W., Thevis M., Br. J. Sports Med., 2014, Vol. 48, pp. 820-826. DOI: 10.1136/bjsports-2014-093526.

3. Gao W., Dalton J.T., Drug Discov. Today, 2007, Vol. 12, pp. 241-248. DOI: 10.1016/j.drudis.2007.01.003

4. Choi S.M., Lee B.M., Expert Opin. Drug Saf., 2015, Vol. 14, pp. 1773-1785. DOI: 10.1517/14740338.2015.1094052

5. Geldof L., Deventer K., Roels K., Tudela E. et al., Int. J. Mol. Sci., 2016, Vol. 17, pii: E1676. DOI: 10.3390/ijms17101676

6. Constanzer M.L., Chavez-Eng C.M., Matuszewski B.K., J. Chromatogr. B. Biomed. Sci. Appl., 1997, Vol. 693, pp. 131-137.

7. World Anti-Doping Agency. The World Anti-Doping Code. The 2019 Prohibited List. International Standard. Available at: https://www.wada-

Дмитриева Екатерина Владимировна - аспирант кафедры аналитической химии, Кубанский государственный университет, Краснодар

Азарян Алиса Андреевна - сотрудник кафедры аналитической химии, Кубанский государственный университет, Краснодар
8. Thevis M., Geyer H., Kamber M., Schänzer W. // Drug Test. Anal. 2009. Vol. 1. pp. 387392.

9. Krug O., Thomas A., Walpurgis K., Piper T. et al. // Eur. J. Clin. Pharmacol. 2014. Vol. 70. pp. 1303-1311.

10. Tsarouhas K., Kioukia-Fougia N., Papalexis P., Tsatsakis A. et al. // Food Chem. Toxicol. 2018. Vol. 115. pp. 447-450.

11. World Anti-Doping Agency. 2017 Anti-Doping Testing Figures. Режим доступа: https://www.wadaama.org/sites/default/files/resources/files/2017 anti-doping_testing_figures_en_0.pdf (дата обращения: 19.08.2019).

12. Thevis M., Piper T., Dib J., Lagojda A. et al. // Rapid Commun. Mass Spectrom. 2017. Vol. 31. pp. 1175-1183.

ama.org/sites/default/files/wada_2019_english_ prohibited_list.pdf (accessed 19 August 2019).

8. Thevis M., Geyer H., Kamber M., Schänzer W., Drug Test. Anal., 2009, Vol. 1, pp. 387-392. DOI: $10.1002 / \mathrm{dta} .91$

9. Krug O., Thomas A., Walpurgis K., Piper T. et al., Eur. J. Clin. Pharmacol., 2014, Vol. 70, pp. 1303-1311. DOI: 10.1007/s00228-0141743-5

10. Tsarouhas K., Kioukia-Fougia N., Papalexis P., Tsatsakis A. et al., Food Chem. Toxicol., 2018, Vol. 115, pp. 447-450. DOI: 10.1016/j.fct.2018.03.043

11. World Anti-Doping Agency. 2017 Anti-Doping Testing Figures. Available at: https://www.wadaama.org/sites/default/files/resources/files/2017_ anti-doping_testing_figures_en_0.pdf (accessed 19 August 2019).

12. Thevis M., Piper T., Dib J., Lagojda A. et al., Rapid Commun. Mass Spectrom., 2017, Vol. 31, pp. 1175-1183. DOI: 10.1002/rcm.7886

Dmitrieva Ekaterina V. - Ph.D. student, analytical chemistry department, Kuban State University, Krasnodar, e-mail: rine_dmitrieva@outlook.com

Azaryan Alice A. - analytical chemistry department employee, Kuban State University, Krasnodar, e-mail: lis_ka@mail.ru 